\title{
Access to Care and Optimal Treatment of Chronic Hepatitis B in Asian Americans: An Evolving Agenda
}

\author{
Emmet B. Keeffe
}

Published online: 6 August 2011

(C) Springer Science+Business Media, LLC 2011

Chronic hepatitis B (CHB) is an important public health problem and a leading cause of liver-related morbidity and mortality worldwide, particularly in the Asia Pacific region [1]. In the US, it has been estimated that 1.25 million individuals, or $0.4 \%$ of the population, are infected with the hepatitis B virus (HBV) [2]. However, during the past two decades, a large number of foreign-born persons have immigrated to the US from areas where the prevalence rate of chronic HBV infection is high, including, in particular, Asia, but, also, the middle East and Africa. This pattern of immigration has contributed to an increased prevalence of chronic HBV infection, which is evident in urban areas and communities with a high Asian immigrant population. Screening programs conducted on Asian Americans in San Francisco and New York City showed that approximately $10 \%$ of newly tested persons have chronic HBV infection $[3,4]$, leading to a revised estimate that 2 million people in the US have chronic HBV infection [5]. A recent encouraging study of trends in the prevalence of HBV infection in the US shows that the HBV prevalence rate decreased among children, which reflects the impact of global and domestic vaccination programs; however, the prevalence rate of chronic HBV infection changed little among adults [6]. Many of these adults are Asian Americans whose cumulative rate of morbidity and mortality from cirrhosis and hepatocellular carcinoma (HCC) is high, based on their infection as neonates or in early childhood [1]. Thus, it is timely that two articles in this issue of Digestive Diseases and Sciences address the challenges of increasing the

\section{E. B. Keeffe $(\square)$}

Division of Gastroenterology and Hepatology,

Department of Medicine, Stanford University Medical Center, 750 Welch Road, Suite 210, Palo Alto, CA 94304-1509, USA

e-mail: ekeeffe@stanford.edu detection rate of $\mathrm{HBV}$ infection in Asian Americans and proposes a consensus recommendation for the treatment of Asian Americans with CHB [7, 8].

$\mathrm{Hu}$ et al. [7] point out that the Asian American immigrant population is rapidly expanding in the US and is projected to continue this pace of growth. Routine screening for $\mathrm{HBV}$ infection can identify those Asian Americans who are infected and potential candidates for antiviral therapy and/or routine surveillance for HCC, as well as those without infection or immunity, who should undergo vaccination. The excellent review by $\mathrm{Hu}$ et al. [7] describes a number of factors that are potential obstacles to screening for hepatitis B in the Asian American population, including patient barriers (lack of knowledge of hepatitis B, limited English language proficiency, cultural beliefs, social stigma, and perceived costs), provider barriers (underestimate of the risk of $\mathrm{HBV}$ infection in Asian Americans, incorrect use of screening tests, and lack of knowledge regarding the cost-effectiveness of screening and the availability of safe and effective therapy), and healthcare system barriers (difficulty navigating the healthcare system and lack or underutilization of health insurance).

This article also coincides with a burgeoning national awareness of the importance of HBV infection to public health that has led to the publication of a national strategy for the prevention and control of hepatitis B (as well as chronic hepatitis C) by the Institute of Medicine [9]. In response to this report, the US Department of Health and Human Services issued on May 12, 2011 its action plan: Combating the Silent Epidemic of Viral Hepatitis. Action Plan for the Prevention, Care and Treatment of Viral Hepatitis [10]. The preamble to this report emphasizes that $65-75 \%$ of infected Americans remain unaware of their viral infection, which is largely preventable. For the first 
time, this agenda of increasing hepatitis awareness is part of the Healthy People 2020 report, and it is hoped that full implementation of this program will, by 2020, increase the proportion of persons who are aware of their HBV infection above the current rate of $33-66 \%$ and eliminate mother-to-child transmission of HBV. In addition to the above programs, a number of bills have been introduced in Congress over the past few years to promote increased awareness and treatment of chronic viral hepatitis.

The recommendations for the identification of $\mathrm{HBV}$ infection published by the Centers for Disease Control and Prevention (CDC) in 2008 broadened previous guidelines for screening and recommended that all persons born in regions with hepatitis $\mathrm{B}$ surface antigen ( $\mathrm{HBsAg}$ ) prevalence rates of $\geq 2 \%$ be tested for the presence of $\mathrm{HBV}$ infection [11]. This directive mandates HBsAg testing of immigrants to the US from $88 \%$ of the world's geographic regions, including $45 \%$ born in high-prevalence regions $(\geq 8 \%)$ and $43 \%$ born in regions of intermediate prevalence $(2-7 \%)$. This recommendation highlights the importance of overcoming the barriers outlined in the article of $\mathrm{Hu}$ et al. [7] so that Asian Americans who are not infected or immune can undergo hepatitis B vaccination, which is more than $90 \%$ effective in preventing HBV infection [11]. $\mathrm{Hu}$ et al. [7] outline a number of measures, including culturally sensitive interventions and educational outreach programs, that may overcome barriers and lead to improved rates of screening. One particularly striking report from San Francisco shows what can be accomplished on the local level by creating a grassroots community coalition of public and private organizations, including the Asian community, the healthcare system, policy makers, businesses, and the general public, to promote testing for hepatitis $\mathrm{B}$, vaccination, and access to treatment [12]. Finally, a recent report using Markov modeling showed that screening, followed by treatment, was cost-effective at the $2 \%$ threshold for the prevalence of chronic HBV infection, as is present in the US, and also likely to be cost-effective in populations with a prevalence as low as $0.3 \%$ [13].

The second article in this issue of Digestive Diseases and Sciences by Tong et al. [8] proposes guidelines for the treatment of CHB in Asian Americans. This set of recommendations is based on a review of the relevant literature and the expert opinion of a panel of Asian American physicians. As international guidelines and a US treatment algorithm on the treatment of CHB have been published for a number of years and regularly updated [14-17], one might ask why is there a need for a specific set of treatment recommendations for Asian Americans, and how do they differ from existing guidelines. The basis for this unique set of recommendations in Asian Americans comes, in a large part, from a study matching the recommended treatment criteria in the four standard guidelines to a 7-year natural history study of 369 predominantly Asian American patients, of whom 37 died or underwent liver transplantation for complications of cirrhosis and 30 developed HCC [18]. This retrospective analysis showed that only 20-60\% of those who developed HCC and $27-70 \%$ of those with liver complications leading to death or transplantation would have been identified as candidates for antiviral therapy using the recommendations from the four guidelines. The addition of a serum albumin level less than $3.5 \mathrm{~g} / \mathrm{dl}$ and platelet count less than $130,000 / \mathrm{mm}^{3}$ to existing guidelines would lead to identification of $89-100 \%$ of those who died of non-HCC complications of chronic liver disease and 96-100\% who developed HCC for antiviral therapy. If precore or basal core promoter (BCP) mutations were also included, then $100 \%$ of those who developed HCC would meet the criteria for treatment [18].

The first distinction from existing guidelines in the publication by Tong et al. [8] is that only entecavir and tenofovir are recommended as first-line treatments, whereas the other guidelines also include peginterferon alfa-2a as a first-line option. This recommendation very likely takes into account the low usage rate of peginterferon alfa-2a in the US. However, the authors indicate in the body of their text that peginterferon alfa-2a may be considered in patients with hepatitis $\mathrm{B}$ e antigen ( $\mathrm{HBeAg}$ )positive $\mathrm{CHB}$ if a finite period of treatment is desired, such as young women who are considering a future pregnancy or patients unwilling to commit to long-term antiviral therapy.

The indications for antiviral therapy are generally similar to existing guidelines [14-17] in the Tong et al. [8] set of recommendations for patients with $\mathrm{HBeAg}$-positive or -negative CHB: serum HBV DNA level >2,000 IU/ml and alanine aminotransferase (ALT) levels above the upper limit of normal (ULN), although some guidelines suggest $>2$ times the ULN for ALT levels [14, 16]. For HBeAg-negative patients with a HBV DNA level $>2,000 \mathrm{IU} / \mathrm{ml}$ and a normal ALT level, liver biopsy is recommended; this recommendation is also generally similar to existing guidelines, with age $>35$ or 40 years often suggested as a trigger for biopsy. However, for patients in this "gray zone" who refuse liver biopsy, Tong et al. [8] recommend the use of a "risk impact scoring system" that includes age, gender, BCP mutations, $\mathrm{HCC}$ in first-degree relatives, and a low serum albumin level or platelet count. Points are allocated to these parameters, and the total point score is used to determine if treatment is indicated. While the majority of these elements, with the exception of the serum albumin and platelet count, are taken into consideration in existing guidelines, this risk score by Tong et al. [8] will need to be verified in prospective testing. Finally, similar to most guidelines, patients with $\mathrm{CHB}$ and cirrhosis and any detectable HBV DNA should be treated. 
In summary, the recommendations for the antiviral treatment of Asian Americans are practical and, generally, similar to existing guidelines, except for the addition of serum albumin, platelet count, and BCP mutations in HBeAg-negative patients with normal ALT levels. The use of a numerical risk impact scoring system is novel, but will require further testing in order to confirm its validity. The publications of $\mathrm{Hu}$ et al. [7] and Tong et al. [8] in this issue add to the encouraging momentum toward recognizing the importance of CHB in Asian Americans, i.e., the detection of infection by higher rates of screening and tailored therapy encompassing a greater proportion of patients who are likely to benefit from lower rates of cirrhosis and HCC.

\section{References}

1. Ganem D, Prince AM. Hepatitis B virus infection-natural history and clinical consequences. $N$ Engl J Med. 2004;350: 1118-1129.

2. McQuillan GM, Coleman PJ, Kruszon-Moran D, Moyer LA, Lambert SB, Margolis HS. Prevalence of hepatitis B virus infection in the United States: the National Health and Nutrition Examination Surveys, 1976 through 1994. Am J Public Health. 1999;89:14-18.

3. Centers for Disease Control and Prevention (CDC). Screening for chronic hepatitis B among Asian/Pacific Islanders populationsNew York City, 2005. MMWR Morb Mortal Wkly Rep. 2006;55: 505-509.

4. Lin SY, Chang ET, So SK. Why we should routinely screen Asian American adults for hepatitis B: a cross-sectional study of Asians in California. Hepatology. 2007;46:1034-1040.

5. Cohen C, Evans AA, London WT, Block J, Conti M, Block T. Underestimation of chronic hepatitis B virus infection in the United States of America. J Viral Hepat. 2008;15:12-13.

6. Wasley A, Kruszon-Moran D, Kuhnert W, Simard EP, Finelli L, McQuillan G, Bell B. The prevalence of hepatitis B virus infection in the United States in the era of vaccination. $J$ Infect Dis. 2010;202:192-201.
7. Hu KQ, Pan C, Goodwin D. Barriers to screening for hepatitis B virus infection in Asian Americans. Dig Dis Sci. (Epub ahead of print). doi:10.1007/s10620-011-1840-6.

8. Tong MJ, Pan CQ, Hann HW, et al. The management of chronic hepatitis B in Asian Americans. Dig Dis Sci. (Epub ahead of print). doi:1007/s10620-011-1841-5.

9. Colvin HM, Mitchell AE, eds. Hepatitis and Liver Cancer. A national strategy for prevention and control of hepatitis B and C. Washington, DC: The National Academies Press; 2010.

10. Combating the Silent Epidemic of Viral Hepatitis. Action plan for the Prevention, Care and Treatment of Viral Hepatitis. Washington, DC: US Department of Health and Human Services, 2011.

11. Mast EE, Margolis HS, Fiore AE, Brink EW, Goldstein ST, Wang SA, Moyer LA, Bell BP, Alter MJ; Advisory Committee on Immunization Practices (ACIP). A comprehensive immunization strategy to eliminate transmission of hepatitis B virus infection in the United States: recommendations of the Advisory Committee on Immunization Practices (ACIP) part 1: immunization of infants, children, and adolescents. MMWR Recomm Rep. 2005;54:1-31.

12. Bailey MB, Shiau R, Zola J, Fernyak SE, Fang T, So SK, Chang ET. San Francisco hep B free: a grassroots community coalition to prevent hepatitis B and liver cancer. J Commun Health. 2011; 36:538-551.

13. Eckman MH, Kaiser TE, Sherman KE. The cost-effectiveness of screening for chronic hepatitis B infection in the United States. Clin Infect Dis. 2011;52:1294-1306.

14. Lok AS, McMahon BJ. Chronic hepatitis B: update 2009. Hepatology. 2009;50:661-662.

15. European Association For The Study Of The Liver. EASL clinical practice guidelines: management of chronic hepatitis B. J Hepatol 2009;50:227-242.

16. Liaw YF, Leung N, Kao JH, Piratvisuth T, Gane E, Han KH, Guan R, Lau GK, Locarnini S; for the Chronic Hepatitis B Guideline Working Party of the Asian-Pacific Association for the Study of the Liver. Asian-Pacific consensus statement on the management of chronic hepatitis B: a 2008 update. Hepatol Int. 2008;2:263-283.

17. Keeffe EB, Dieterich DT, Han SH, Jacobson IM, Martin P, Schiff ER, Tobias H. A treatment algorithm for the management of chronic hepatitis B virus infection in the United States: 2008 update. Clin Gastroenterol Hepatol. 2008;6:1315-1341.

18. Tong MJ, Hsien C, Hsu L, Sun HE, Blatt LM. Treatment recommendations for chronic hepatitis B: an evaluation of current guidelines based on a natural history study in the United States. Hepatology. 2008;48:1070-1078. 